\title{
Importance of age in prehospital and hospital mortality of heart attacks
}

\author{
R G WILCOX, J R HAMPTON \\ From Department of Medicine, University of Nottingham
}

SUMMARY Prehospital and hospital fatality rates were calculated for each 10-year age group of 2788 patients transported to hospital with heart attacks. The prehospital fatality rate rose progressively from 4 per cent in the youngest age group to 45 per cent in the oldest. There was no age-related difference between the groups in the interval between the onset of symptoms and the first call for help, and a similar proportion of each group summoned a general practitioner. Among those admitted to hospital there was a progressive rise with age in the proportion eventually found to have had a definite or probable myocardial infarction, and among such patients the hospital fatality rate rose from 8 per cent in the youngest group to 35 per cent in the oldest. There was a progressive rise with age in the symptoms and signs of, and treatment for, heart failure.

Reported fatality rates from myocardial infarction can only be interpreted if the ages of the patients are known in detail.

The importance of taking into account a patient's age when assessing his chances of surviving a myocardial infarction was pointed out by Peel in $1955 .^{1}$ Since then age has been incorporated into several "prognostic indices"2-5 yet papers continue to appear which claim very low hospital fatality rates for patients with myocardial infarction with little or no mention of the age of the population studied. ${ }^{6} 7$ In this paper we re-emphasise the extreme importance of the patients' ages in any study of the outcome of myocardial infarction.

\section{Methods}

All patients who required admission for emergency medical problems in Nottingham and its surroundings are referred to the two teaching hospitals. During a four-year period between 1973 and 1977 data were collected daily by a non-medical graduate research assistant on all patients referred to these hospitals with suspected heart attacks. The patients were identified from ambulance and hospital admission records, and were followed up until they died in, or were discharged from, hospital. Coroners' records were inspected for any patient who died before admission, so that those who had had a myocardial infarction could be identified.

After a patient's death or discharge the data Received for publication 16 May 1980 collected, together with copies of all electrocardiograms and the discharge summary or necropsy report, were inspected by a physician (JRH) and the patient was either excluded from the study if he or she had been found to have some disease other than a heart attack, or was placed in one of the following five diagnostic categories.

(i) Definite myocardial infarction-patients with a convincing history of myocardial infarction together with unequivocal electrocardiographic abnormalities (appearance of $Q$ wave and sequential ST segment changes) and a rise in cardiac enzyme values to greater than double the normal upper limit. Patients were also included in this category if there was definite necropsy evidence of myocardial infarction.

(ii) Probable myocardial infarction-patients with a convincing clinical history together with either unequivocal electrocardiographic abnormalities or a rise in plasma cardiac enzyme levels to greater than twice the normal upper limit. Patients were also included in this category if there was necropsy evidence of coronary artery disease but no other cause was found for death.

(iii) Possible myocardial infarction-patients with a convincing history together with an abnormal electrocardiogram that was not typical of recent myocardial infarction, or a rise in serum enzyme 
Table 1 Number of patients in each 10-year age group who were found dead on arrival in hospital

\begin{tabular}{lllllllll}
\hline Age group & $\leqslant 34$ & $35-$ & $45-$ & $55-$ & $65-$ & $75-$ & $85-$ & Total \\
\hline $\begin{array}{l}\text { Number of patients } \\
\text { \% men }\end{array}$ & 23 & 156 & 588 & 886 & 810 & 283 & 42 & 2788 \\
$\begin{array}{l}\text { \% patients at home when } \\
\text { symptoms began }\end{array}$ & 68 & 89 & 84 & 78 & 68 & 51 & 52 & 74 \\
$\begin{array}{l}\text { Dead on arrival at hospital } \\
(\%)\end{array}$ & $1(4 \%)$ & $23(15 \%)$ & $89(15 \%)$ & $189(21 \%)$ & $261(32 \%)$ & $123(43 \%)$ & $19(45 \%)$ & $705(25 \%)$ \\
\hline
\end{tabular}

levels which did not reach twice the upper limit of normal.

(iv) Ischaemic heart disease-patients with a clear history of previous myocardial infarction or angina, together with an abnormal electrocardiogram but nothing to suggest a recent change, and with normal serum enzyme values.

(v) Chest pain of uncertain cause-patients for whom no adequate diagnosis could be made.

Categories (i) and (ii) combined correspond approximately to the WHO definition of definite myocardial infarction.

The data were transferred to 80 column cards and analysed by computer.

\section{Results}

\section{(1) PREHOSPITAL EVENTS}

Studies were made on 2788 patients, and Table 1 shows the number in each 10 -year age group. Of the patients aged 44 and below, 87 per cent were men, but with increasing age the proportion of women rose and in the groups aged 75 or over, and 85 or over, there were equal numbers of men and women (Table 1). Seven hundred and five $(25 \%)$ patients were found to be dead on arrival at hospital, and the prehospital fatality rate increased progressively with age so that among the oldest age group 45 per cent of the patients were dead on arrival. Within each age group the prehospital fatality rate was similar for men and for women.

Table 1 shows that in all age groups except the two oldest, about two-thirds of the patients called for help from their homes. In most cases the symptoms of the heart attack began while the patient was at home, but among the younger age groups there were some patients who developed chest pain at work but delayed calling for help until they had returned home. The first call for help was made to a general practitioner by $1390(50 \%)$ of the patients and for the remainder an emergency ambulance was summoned directly by a member of the public. There was a distinct difference in this respect between patients who were found to be dead on arrival at hospital and those who were admitted. Among those who died before admission a general practitioner was called to between 0 and 13 per cent of the different age groups, without any age-related pattern. Among those who were admitted to hospital, the initial call for help was made to a general practitioner in 62 to 67 per cent of patients. More elderly patients were found dead on arrival at hospital, so in the group as a whole emergency ambulances were summoned to a higher proportion of elderly people.

There were also distinct differences between those patients who were dead on arrival and those who were admitted to hospital in terms of the interval between the onset of symptoms and the first call for help. Among those found dead on arrival, an ambulance had been summoned within 30 minutes of the onset of symptoms for between 69 and 89 per cent of patients in the different age groups. No information could be obtained in $106(15 \%)$ of these 705 patients, mainly because they lived alone and were found dead; there was, however, no trend to suggest that the older patients who were dead on arrival at hospital delayed longer than the younger ones before calling for help. There was a much greater interval between the onset of symptoms and

Table 2 Duration of symptoms before the call for help among patients admitted to hospital

\begin{tabular}{|c|c|c|c|c|c|c|c|}
\hline Age group & $\leqslant 34$ & $35-$ & $45-$ & $55-$ & $65-$ & $75-$ & $85-$ \\
\hline $\begin{array}{l}\text { Call for help (cumulative \%) } \\
\text { Within } 30 \text { minutes } \\
\text { Within } 1 \frac{1}{\text { g hours }} \\
\text { Within } 4 \text { hours } \\
\text { Within } 10 \text { hours }\end{array}$ & $\begin{array}{r}4 \\
44 \\
48 \\
75\end{array}$ & $\begin{array}{l}25 \\
42 \\
68 \\
80\end{array}$ & $\begin{array}{l}16 \\
38 \\
58 \\
71\end{array}$ & $\begin{array}{l}16 \\
37 \\
57 \\
72\end{array}$ & $\begin{array}{l}20 \\
40 \\
59 \\
66\end{array}$ & $\begin{array}{l}16 \\
35 \\
68 \\
85\end{array}$ & $\begin{array}{l}16 \\
48 \\
54 \\
81\end{array}$ \\
\hline$\%$ calling for help after 10 hours & 25 & 20 & 29 & 28 & 34 & 15 & 19 \\
\hline
\end{tabular}




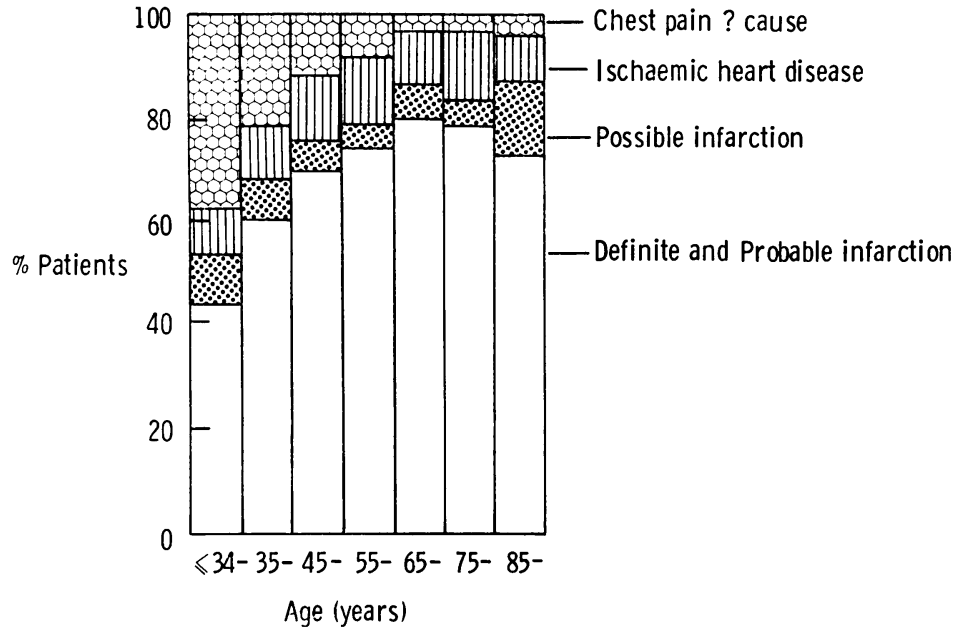

Fig. Percentage of patients in each age group with the different diagnostic categories of heart attack.

the first call for help among patients who reached hospital alive than among those who were found dead on arrival. Table 2 shows the intervals between the onset of symptoms and the call for an ambulance in the patients who were admitted to hospitals and in whom the duration of the symptoms was known (96.4\% of those admitted). There was no difference between the age groups, 50 per cent of each group having called for help by between one and a half and four hours after the onset of symptoms. The time taken for an ambulance to respond to the call and to transport the patient to hospital was also similar in each group, and there was nothing to suggest that elderly people were handled with less urgency than younger ones.

\section{(2) HOSPITAL EVENTS}

The Figure shows that with increasing age the proportion of patients eventually found to have had definite, probable, or possible myocardial infarctions increased progressively from 54 per cent in those aged 34 or less, to 87 per cent in those aged 85 or more. The proportion of patients eventually considered to have ischaemic heart disease without infarction varied from 9 to 14 per cent without any age-related pattern, but the proportion of patients in whom no adequate cause of chest pain could be found fell from 36 per cent in the youngest patients to 4 per cent in the oldest.

Table 3 shows the number of people in each age group who were admitted to hospital, who had a diagnosis of definite or probable myocardial infarction, and who died from their infarction. The fatality rates from myocardial infarction show a small increase to age 64 years, and a pronounced increase thereafter. The death rate from myocardial infarction was 31 per cent in patients aged 65 years or more, and 16 per cent in those aged 64 years or less. Patients aged 65 or more accounted for 35 per cent of all admissions, 38 per cent of all infarctions, and 55 per cent of all the deaths from infarction.

The proportion of patients known to have had previous myocardial infarction varied from 8 to 31 per cent in the different age groups (mean for all ages, $28 \%$ ), and there was no age-related trend. Similarly there was no age-related pattern of difference in the numbers of patients recorded as complaining of chest pain (87 to $96 \%$ in the different age groups) or of breathlessness (38 to $58 \%$ ). Table 4 shows that there was no age-related pattern in the

Table 3 Number of patients in each age group who were admitted to hospital, number who had definite or probable myocardial infarction, and \% deaths among those with either definite or probable infarction

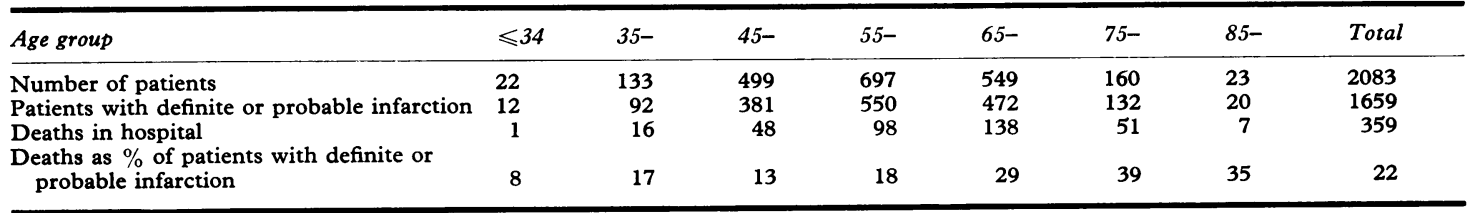


Table 4 Electrocardiographic position of infarction in patients with definite or probable myocardial infarction

\begin{tabular}{|c|c|c|c|c|c|c|c|c|}
\hline Age group & $\leqslant 34$ & $35-$ & $45-$ & $55-$ & $65-$ & $75-$ & $85-$ & Total \\
\hline $\begin{array}{l}\text { Number of patients } \\
\text { Percentage with anterior or lateral infarction } \\
\text { Percentage with inferior or posterior infarction } \\
\text { Percentage with no definite electrocardiographic } \\
\text { evidence of infarction }\end{array}$ & $\begin{array}{l}12 \\
83 \\
17\end{array}$ & $\begin{array}{l}92 \\
47 \\
37\end{array}$ & $\begin{array}{r}381 \\
48 \\
42\end{array}$ & $\begin{array}{r}550 \\
51 \\
39\end{array}$ & $\begin{array}{r}472 \\
47 \\
33\end{array}$ & $\begin{array}{r}132 \\
52 \\
24\end{array}$ & $\begin{array}{l}20 \\
35 \\
25\end{array}$ & $\begin{array}{r}1659 \\
49 \\
37\end{array}$ \\
\hline
\end{tabular}

proportion of patients of different ages with anterior infarctions on the electrocardiogram but a slightly lower proportion of the older patients had inferior infarcts. Table 5, however, shows that with increasing age more patients were found to have raised jugular venous pressure, peripheral oedema, basal lung crepitations, or an arrhythmia of some kind. Elderly patients were more often given digoxin and diuretics than younger ones.

The average duration of hospital stay in the whole group was 10 days. Nine per cent of those aged 75 to 84 , and 16 per cent of those aged 85 or over, stayed in hospital more than three weeks, but less than 5 per cent in all other age groups were kept in hospital for this length of time.

\section{Discussion}

If an ambulance is called to a patient with suspected myocardial infarction the patient's chances of dying depend on his age. There are more prehospital deaths among old people than among young ones, and there is a higher hospital mortality from myocardial infarction among the elderly. Though we collected data on all the patients transported to hospital by ambulance, ours was not a complete community study, for we have no information about the patients who had undiagnosed myocardial infarction and survived, or who had fatal infarction, death being certified by a general practitioner who summoned a hearse rather than an ambulance, or about those in whom infarction was diagnosed but who were treated at home. Nevertheless, our results are similar to those of smaller studies where all cases of myocardial infarction have been registered. ${ }^{8}$

It is clear that the effect of age on mortality is not caused by the behaviour of the patients or their doctors. In all age groups except the very old about two-thirds of patients were at home when they developed their symptoms. Similar proportions of each age group called for help from a general practitioner. The delay between onset of symptoms and a call for help was not affected by age, nor did it alter the speed of the response by the ambulance. We have previously shown that though old people are less likely to be admitted to a coronary care unit than young ones, this does not influence mortality. ${ }^{\circ}$

The only things that seem to characterise the elderly patients with myocardial infarction are greater frequencies of heart failure and arrhythmias than in the younger ones. The increasing frequency of heart failure in the older age groups might be related to the increasing fatality rate with age in one of two ways. First, older people may suffer more myocardial damage than young ones when an infarction occurs, so that the infarction causes both a higher fatality rate and an increased incidence of heart failure in those who survive. Alternatively, older people may be more likely than younger ones to have pre-existing heart failure from a variety of causes, so that an infarction is less well tolerated.

A district general hospital that admits all types of patients with heart attacks is likely to deal with many more elderly people than a specialist cardiac centre, to which young patients will almost certainly be selectively referred. There is little convincing evidence that during the past 10 years hospital

Table 5 Percentage of patients in different age groups with various clinical signs on admission, percentage in whom arrhythmias were detected, and percentage given digoxin and diuretics during hospital stay

\begin{tabular}{|c|c|c|c|c|c|c|c|}
\hline Age group & $\leqslant 34$ & $35-$ & $45-$ & $55-$ & $65-$ & $75-$ & $85-$ \\
\hline $\begin{array}{l}\text { Number of patients } \\
\text { Percentage with raised jugular venous pressure } \\
\text { Percentage with peripheral oedema } \\
\text { Percentage with any arrhythmia } \\
\text { Percentage given digoxin } \\
\text { Percentage given diuretics }\end{array}$ & $\begin{array}{r}22 \\
9 \\
0 \\
22 \\
27 \\
27\end{array}$ & $\begin{array}{r}133 \\
10 \\
1 \\
25 \\
20 \\
21\end{array}$ & $\begin{array}{r}499 \\
11 \\
6 \\
26 \\
22 \\
36\end{array}$ & $\begin{array}{r}697 \\
19 \\
5 \\
32 \\
35 \\
49\end{array}$ & $\begin{array}{r}549 \\
22 \\
14 \\
38 \\
37 \\
56\end{array}$ & $\begin{array}{r}160 \\
30 \\
20 \\
32 \\
46 \\
70\end{array}$ & $\begin{array}{l}23 \\
33 \\
35 \\
52 \\
39 \\
43\end{array}$ \\
\hline
\end{tabular}


admission has led to a real reduction in mortality rates from myocardial infarction ${ }^{10}$ and claims of very low fatality rates from specialist centres must be regarded with caution unless detailed information is provided about the age of the patients treated.

\section{References}

1 Peel AAF. Age and sex factors in coronary artery disease. Br Heart $\mathcal{F}$ 1955; 17: 319-26.

2 Pell S, D'Alonzo CA. Immediate mortality and five-year survival of employed men with a first myocardial infarction. $N$ Engl $\mathcal{F}$ Med 1964; 270: 915-22.

3 Norris RM, Caughey DE, Mercer CJ, Scott PJ. Prognosis after myocardial infarction: six year follow up. $\mathrm{Br}$ Heart $\mathcal{F}$ 1974; 36: 786-90.

4 Kitchin AH, Pocock SJ. Prognosis of patients with acute myocardial infarction admitted to a coronary care unit: I. survival in hospital. Br Heart $\mathcal{F}$ 1977; 39; 1163-6.
5 Henning H, Gilpin EA, Covell JW, Swan EA, O'Rourke RA, Ross J Jr. Prognosis after acute myocardial infarction: a multivariate analysis of mortality and survival. Circulation 1979 ; 59: 1124-36.

6 O'Rourke MF, Walsh B, Fletcher M, Crowley A. Impact of the new generation coronary care unit. Br Med f 1976; iii: 837-9.

7 Chapman BL. Effect of coronary care on myocardial infarct mortality. Br Heart $\mathcal{f} 1979$; 42: 386-95.

8 Tunstall-Pedoe $\mathrm{H}$. Uses of coronary heart attack registers. Br Heart $\mathcal{f}$ 1978; 40: 510-15.

9 Hill JD, Holdstock G, Hampton JR. Comparison of mortality of patients with heart attacks admitted to a coronary care unit and an ordinary medical ward. Br Med F 1977; ii: 81-83.

10 Rose G. The contribution of intensive coronary care. Br F Prev Soc Med 1975; 29: 147-50.

Requests for reprints to Professor J R Hampton, Department of Medicine, Floor D, University Hospital, Queen's Medical Centre, Nottingham NG7 2UH. 